\title{
Comparative Intradermal Tuberculin Testing of Free-Ranging African Buffaloes (Syncerus caffer) Captured for Ex Situ Conservation in the Kafue Basin Ecosystem in Zambia
}

\author{
Hetron Mweemba Munang'andu, ${ }^{1}$ Victor Siamudaala, ${ }^{2}$ Wigganson Matandiko, ${ }^{2}$ \\ Andrew Nambota, ${ }^{3}$ John Bwalya Muma, ${ }^{3}$ Aaron Simanyengwe Mweene, ${ }^{3}$ \\ and Musso Munyeme ${ }^{3}$ \\ ${ }^{1}$ Section of Aquatic Medicine and Nutrition, Department of Basic Sciences and Aquatic Medicine, \\ Norwegian School of Veterinary Sciences, Ullevålsveien 72, P.O. Box 8146, 0033 Oslo, Norway \\ ${ }^{2}$ Information and Planning Unit, Department of Research, Zambia Wildlife Authority, Private Bag 1, Chilanga, Zambia \\ ${ }^{3}$ Department of Disease Control, School of Veterinary Medicine, University of Zambia, P.O. Box 32379, Lusaka 10101, Zambia
}

Correspondence should be addressed to Musso Munyeme, munyeme@yahoo.co.uk

Received 20 January 2011; Revised 2 April 2011; Accepted 27 April 2011

Academic Editor: Jesse M. Hostetter

Copyright (c) 2011 Hetron Mweemba Munang'andu et al. This is an open access article distributed under the Creative Commons Attribution License, which permits unrestricted use, distribution, and reproduction in any medium, provided the original work is properly cited.

\begin{abstract}
Bovine tuberculosis (BTB) is endemic in African buffaloes (Syncerus caffer) in some National Parks in Southern Africa, whilst no studies have been conducted on BTB on buffalo populations in Zambia. The increased demand for ecotourism and conservation of the African buffalo on private owned game ranches has prompted the Zambian Wildlife Authority (ZAWA) and private sector in Zambia to generate a herd of "BTB-free buffaloes" for ex situ conservation. In the present study, 86 African buffaloes from four different herds comprising a total of 530 animals were investigated for the presence of BTB for the purpose of generating "BTB free" buffalo for ex-situ conservation. Using the comparative intradermal tuberculin test (CIDT) the BTB status at both individual animal and herd level was estimated to be $0.0 \%$ by the CIDT technique. Compared to Avian reactors only, a prevalence of $5.8 \%$ was determined whilst for Bovine-only reactors a prevalence of $0.0 \%$ was determined. These results suggest the likelihood of buffalo herds in the Kafue National Park being free of BTB.
\end{abstract}

\section{Introduction}

Bovine tuberculosis (BTB) has emerged to be a significant threat to wildlife conservation in sub-Saharan Africa as it affects several wildlife species especially African buffalo (Syncerus caffer) and Kafue lechwe (Kobus leche Kafuensis) [1-5]. Demographical factors such as group composition of the herd augmented with gregarious social behavioral pattern under favorable ecological disposition have been identified as major deterministic factors of disease maintenance within particular wildlife species [6-8]. Highly gregarious species that live in large herds such as the African buffalo and the Kafue lechwe (have been shown to have a high intraspecies transmission capacity [4]. Interspecies transmission between prey species and predators has been reported in the Kruger National Park while close contact between wild ungulates and livestock is reported to be the cause of interspecies transmission at the interface areas [5]. In certain endemic wildlife populations, the disease has been associated with high mortalities that have been linked to population reductions $[4,5]$. Given that the eradication of BTB in infected populations is not easy, the disease poses a significant challenge to wildlife conservation. Hence, it is imperative to reduce the risk of introducing BTB to naïve wildlife populations.

The expansion of ex situ conservation in Zambia has been affected by the general absence of "Africa's big five," namely, the lion (Panthera leo), leopard (Panthera pardus), elephant (Loxodonta africana), rhino (Diceros bicornis), and African buffalo (Syncerus caffer) on game ranches. The prohibitive 
legislature leading to the absence of wild cats such as the lion, leopard and cheetah on most game ranches is for obvious reasons that in the absence of adequate protective measures wild cats are a serious threat to the general public as most game ranches are located in areas close to human habitation. Besides, most game ranches do not stock enough prey species for the survival of superpredators like lions, leopards, and cheetahs. Elephants are not kept on game ranches since most game ranches are too small to support large herds. This leaves the African buffalo as the only species of the "big five" that can be reared on game ranches. Apart from increasing revenues from ecotourism and safari hunting, rearing of buffalo on game ranches has several ecological benefits that would contribute to the conservation of other species [9]. The other main benefit of buffaloes on a game ranch is that they easily open up thickets and other inaccessible dense vegetation by antelope species through their mixed feeding as bulk grazers and browsers. Besides, rearing of buffaloes on game ranches is strongly supported as a positive ex situ conservation strategy that would help increase the declining buffalo populations due to poaching and uncontrolled predation by humans observed in the state owned national parks (NPs). The introduction of buffaloes captured in state owned national parks makes it necessary to screen the animals for infectious diseases like foot and mouth disease (FMD) and BTB to ensure that they are healthy. In the present study, buffaloes captured in the Kafue flats game management area (GMA) were subjected to intradermal tuberculin skin test and were only translocated to game ranches after they were declared free of BTB. We anticipate that these animals will serve as breeding stocks of "BTB-free buffalo herds" for stocking other game ranches in Zambia.

The main aim of this paper is to highlight the tuberculosis situation as it occurs in other animal species within the Kafue basin besides the lechwe antelope species. Further we want to document our current findings to what we may obtain in future given the rising interaction patterns between wild and domestic animals within the Kafue basin.

\section{Materials and Methods}

2.1. Study Area. The study was carried out in an area called Nanzhila which is located in the game management area of the Kafue National Park (Figure 1). The area is a wetland that supports a transhumance grazing system which allows for the coexistence of wildlife and livestock. Nanzhila is located on the western end of the basin approximately $40 \mathrm{~km}$ away from the Lochinvar and Blue lagoon Game Management areas which are endemic with BTB in the Kafue lechwe.

2.2. Capture of the Buffaloes. Seven buffalo herds were captured in the Kafue basin using a helicopter to drive the animals into holding facilities (Capture bomas). Herd size was estimated by taking a mean of three counts of the entire herd brought in the Capture boma. Only animals between one and two years old were captured and included in the study for purpose of generating a breeding stock to be used as a source of buffaloes for other game ranches in future. The selected animals were then driven into quarantine facilities.
There were six quarantine facilities, three on each side of the capture Boma. The facilities were adjacent to the capture Boma where captured animals were diverted for separation as well as holding them for longer periods. The quarantine facilities were fenced with hessian black cloth inside and game fence wire on the outside. They had watering points and feed was provided during the whole capture period. The animals in the quarantine facilities were anaesthetized by darting using M99 (etorphine hydrochloride/Immobilon), a super potent opioid analgesic and were reversed using a very strong opioid antagonist: M5050 (diprenorfin/Revivon,) at standard dosages as recommended by the manufacturer (Novartis, Johannesburg, South Africa). Ages were estimated by tooth development and wear [10] as well as horn development [11]. Each animal was ear-tagged with a unique number. Biological data indicating sex, age, body condition at capture, and herd size were entered in Microsoft excel sheets. The body conditions were subjectively assessed using the degree of exposure of the pelvic bony prominences around the pelvic area with those having a well-padded pelvic area scoring 1, with less or fair scoring 2 whilst those with high prominences or poor scored 3 . Here in the quarantine facilities, the animals were kept for as long as three months.

\subsection{Comparative Intradermal Tuberculin Skin Test. Animals} were cast down using chemical restraint as explained above. Two sites of approximately $8 \mathrm{~cm}$ in diameter in the mid cervical area and approximately 10 to $12 \mathrm{~cm}$ apart, cranialcaudal, were shaved using a Gillette razor blade. The initial skin thicknesses at the two sites were then measured using vernier callipers. A comparative intradermal tuberculin test (CIDT) consisting of avian and bovine purified protein derivative (PPD) antigens (from The Central Veterinary Institute, Lelystad: The Netherlands) was used. The inoculation was carried out using the McLintock Tuberculin Testing equipment which precisely injects $0.1 \mathrm{ml}$ of avian (containing 2,500 international Units) tuberculin (Lelystad) intradermal onto the cranial site and $0.1 \mathrm{ml}$ of mammalian-bovine (containing 5,000 Tuberculin units) tuberculin (Lelystad) intradermal on the caudal site. After inoculation, a small nodule formed on both sites.

After seventy-two hours after inoculation, each animal was chemically restrained by darting using M99 (etorphine hydrochloride/Immobilon) and the same person who took the previous readings took a second measurement of the skin thickness. The effect of theM99 was reversed using a very strong opioid antagonist: M5050 (diprenorfin/Revivon,) at standard dosages as recommended by the manufacturer (Novartis, Johannesburg, South Africa). The skin thickness at the two sites of inoculation was measured and entered on a record sheet. Reactors were classified according to the Office International des Epizooties (OIE) standards of result interpretation [12]. Further, we arbitrarily classified avian only reactors as being negative when an increase in skin thickness of less than $2 \mathrm{~mm}$ PPD is recorded. Inconclusive reactors were indicated by skin thickness increases of between $2 \mathrm{~mm}$ and $4 \mathrm{~mm}$.

A positive reaction for the intradermal comparative test was indicated by an increase in skin thickness at the bovine 


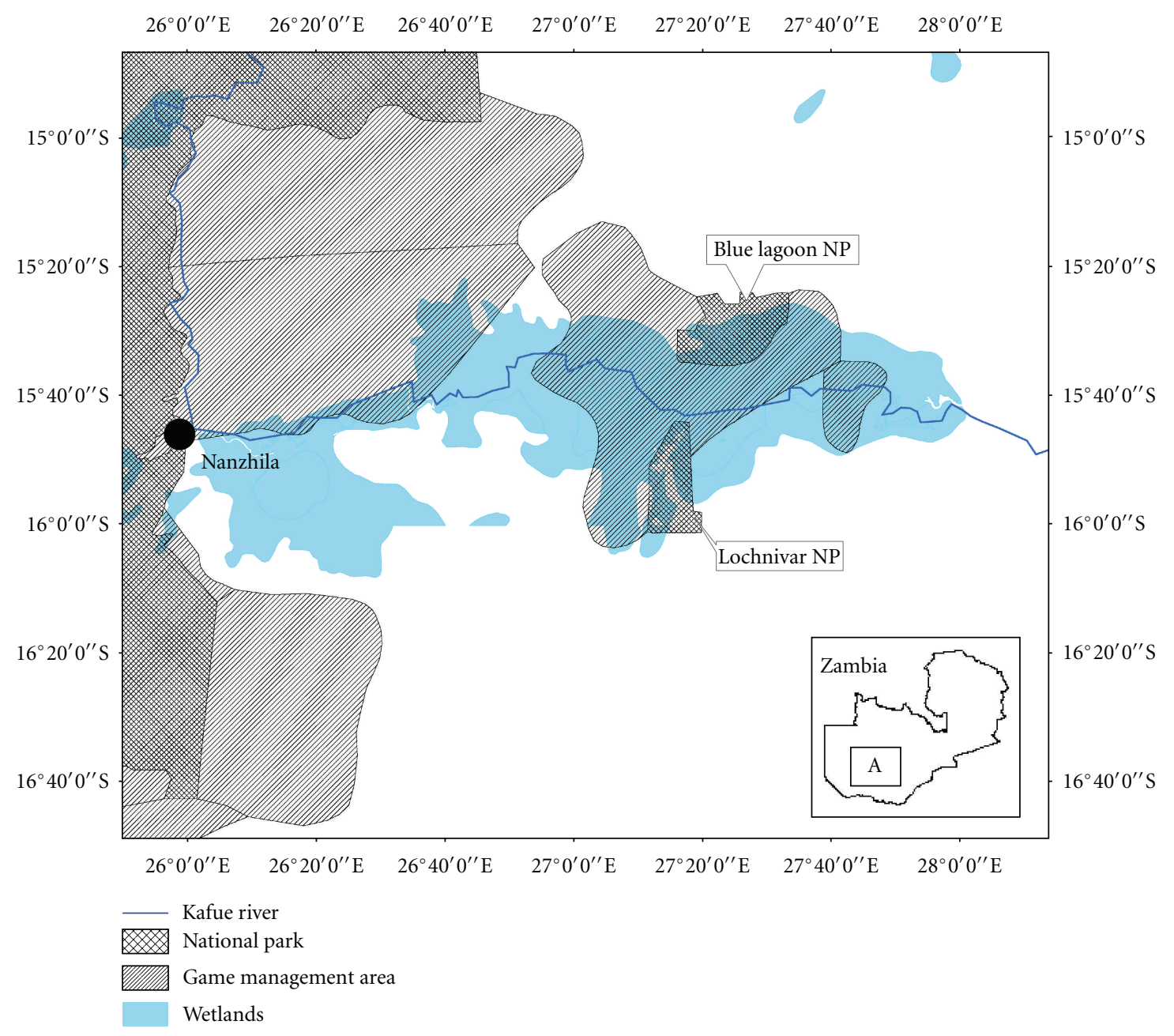

FIGURE 1: Map of the Kafue basin ecosystem with one big black dot (Nanzhila) showing the study site were the buffaloes were captured and quarantined for the BTB intradermal skin test. The insert shows the map of Zambia with A showing the location of the Kafue basin ecosystem.

site of injection of more than $4 \mathrm{~mm}$ greater than the reaction shown at the site of the avian injection. A negative reactor on CIDT was identified when there was a negative reaction to bovine tuberculin, or a positive or inconclusive reaction to bovine tuberculin that was equal to, or less than a positive or inconclusive reaction in avian test and also when negative to both [12]. Only Buffaloes that were negative CIDT were allowed to be translocated to game ranches. Inconclusive reactors were not translocated.

\section{Results}

A total of 86 African buffaloes were captured from 4 apparently different and independent herds (herd no. $1 ;(n=$ 21 animals), herd no $2 ;(n=18$ animals), herd no 3; $(n=11$ animals); herd no 4 ; $(n=36$ animals). All animals (100\%) were negative for BTB on comparative intradermal tuberculin test (Table 1). With Avian reactors only, a prevalence of 5.8\% was determined (Table 1). Across all herds captured, $2.3 \%$ of the buffaloes showed an inconclusive BTB response.

\section{Discussion}

To our knowledge this is the first study on BTB intradermal tuberculin test in buffaloes in Zambia and precisely in the Kafue basin area (Figure 1) $[4,13]$. Using the CIDT, no BTB positive reactors were found. However, the results need to be interpreted with caution given the age range of the animals. Further, the animals used in the present study were obtained from an area located on the western end of the Kafue basin unlike the Lochinvar area located further east, which has been shown to be endemic to BTB in Kafue lechwe antelopes (Figure 1). However, there has been no intradermal-tuberculin screen tests carried out on buffaloes in the Lochinvar NP as routine meat inspections have not indicated presence of the disease in this species of animals. However, it is evident that the disease is endemic in cattle in 
TABLe 1: Overall results based on Avian, Bovine and Comparative tuberculin test reactor animals.

\begin{tabular}{|c|c|c|c|c|c|}
\hline Herd No. & $\begin{array}{c}\text { Total no. of } \\
\text { buffaloes }(N)\end{array}$ & $\begin{array}{l}\text { No. of buffaloes } \\
\text { sampled }(n)\end{array}$ & $\begin{array}{c}\text { Proportion } \\
\text { positive }(\%) \\
\text { Avian reactors } \\
\text { only }\end{array}$ & $\begin{array}{c}\text { Proportion } \\
\text { Inconclusive (\%) } \\
\text { CIDT }\end{array}$ & $\begin{array}{c}\text { Proportion } \\
\text { Positive }(\%) \\
\text { CIDT }\end{array}$ \\
\hline 1 & 213 & 21 & $1(4.8 \%)$ & $0(0.0 \%)$ & $0(0.0 \%)$ \\
\hline 2 & 72 & 18 & $0(0.0 \%)$ & $1(5.6 \%)$ & $0(0.0 \%)$ \\
\hline 3 & 137 & 11 & $1(9.1 \%)$ & $0(0.0 \%)$ & $0(0.0 \%)$ \\
\hline 4 & 108 & 36 & $3(8.3 \%)$ & $1(2.8 \%)$ & $0(0.0 \%)$ \\
\hline Overall & 530 & 86 & $5(5.8 \%)$ & $2(2.3 \%)$ & $0(0.0 \%)$ \\
\hline
\end{tabular}

the area and these are likely to serve as a source of infection for other species apart from the lechwe antelopes, given that the prevalence of BTB in cattle through CIDT was found to be close to $50 \%$ [14]. Hence, it would be interesting to carry out detailed investigations on a larger scale to elucidate factors that have kept the disease in cattle and Kafue lechwe with little or no transmission to other 1 species. On the other hand, these findings are in line with earlier observations made by Munyeme and coworkers [4] that BTB interspecies transmission seems to be restricted in certain regions within the Kafue basin, for example, interface area where cattle and lechwe share grazing pastures. Moreover, if also animals over two years of age would have been included in the testing, more positive reactors might have been found.

Pandey had postulated that cattle on the plains could acquire BTB through contaminated pastures [15]. From this study, buffaloes do not come into direct contact with cattle as do the lechwe antelopes. All the cattle keepers and herdsmen in the Kafue basin have the same observation that cattle will never go close to Buffaloes or Buffaloes come close to cattle, yet lechwe antelopes and cattle will be seen grazing together. Another important observation by both wildlife officers and herdsmen is that lechwe antelopes do not graze near Buffalo herds.

However, the lack of evidence of BTB in Buffaloes that graze in the same cattle grazing grounds without close contact as it obtains in lechwe antelope questions the possibility of acquiring the infection through the oral route. On the other hand, Munyeme and coworkers (2010) found that the disease in both cattle and lechwe is more respiratory than intestinal, which indicates air born route of transmission and thus close contact between animals [4]. However, despite these findings, area attributable deterministic factors of disease occurrence have been found to play a pivotal role in differentiating transmission dynamics of disease patterns $[7,14]$. Other studies have indicated that wildlife reservoirs of $M$. bovis are major sources of infection for grazing cattle in some countries [7]. For instance the Badger (Meles meles) of the United Kingdom and red deer (Cervus elaphus) in New Zealand are biological reservoirs for BTB in these countries [16]. However, our current findings demonstrate a unique difference to these other areas as the disease seems to be more likely to be harboured in cattle than Buffaloes.

With increasing demand for buffaloes in ex situ conservation, it is imperative that animals captured for the purpose of translocation from state owned NPs to game ranches should be tested for the presence of BTB and only animals free of the disease may be translocated to game ranches. This is particularly important for highly gregarious species captured from the Kafue basin being an interface area known to be endemic of the disease both in cattle and the Kafue lechwe $[1,4,5]$. Thus far, about 700 Kafue lechwe have been translocated from the Kafue basin without testing for BTB [17]. Subsequently, BTB was diagnosed from Kafue lechwe and bushbuck on a game in Chisamba [13]. Although it is not known how the disease was introduced on the game ranch, it is likely that the translocated Kafue lechwe from Lochinvar NP to the game ranch could have carried the infection thereby becoming a source of infection to the bushbucks on the game ranch. Game ranches with BTB-infected animals could become a source of transmission to other game ranchers as it is common practice for game ranchers to sell live animals to other game farmers. In the absence of screening tests, it is likely BTB can be transmitted from one game ranch to the other. The ultimate solution is to generate BTB-free herds whenever animals are captured for ex situ conservation from NPs and GMAs.

Detection of positive Mycobacteria avium reactors albeit at a relatively low prevalence intimates the likely presence of other Mycobacteria species. Atypical Mycobacteria species have been reported from Kafue lechwe in the Kafue basin [18]. MacAdams isolated Mycobacteria avium from Kafue lechwe around the Lochinvar NP. As pointed out by Rottcher [18], an environment with warm, humid mud fields appears beneficial for the survival of saprophytic mycobacteria and it would appear that buffaloes and lechwe pick these atypical infections from the environment. However, there is need to carry out more detailed investigation on the presence of other Mycobacteria species in the Kafue basin and to determine their impact on wildlife and domestic animals in the area. In order to increase the sensitivity of the screening procedure, animals can be tested using the gamma interferon assay along with the intradermal skin test although there would be need to validate the sensitivity of both assays in wildlife. As pointed out by others, intradermal tuberculin test has proved to be useful for the diagnosis of BTB in buffaloes and lions in the Kruger NP [19]. The bovine gamma interferon assay has proved to be an alternative to the tuberculin test although its application in wildlife has not been widely explored [20]. Overall, African buffaloes 
and other highly gregarious species captured for ex situ conservation should be screened for the presence of BTB prior to translocation and only noninfected animals should be translocated in order to avoid introducing the disease into new territories.

\section{Acknowledgments}

The authorswant to acknowledge that this work was selffunded by the authors. More importantly, the authors of the paper do not in any way or means have any direct financial relation with the commercial identities mentioned in our paper.

\section{References}

[1] R. G. Bengis, N. P. Kriek, D. F. Keet, J. P. Raath, V. De Vos, and H. F. Huchzermeyer, "An outbreak of bovine tuberculosis in a free-living African buffalo (Syncerus caffer-sparrman) population in the Kruger national park: a preliminary report," Onderstepoort Journal Of Veterinary Research, vol. 63, no. 1, pp. 15-18, 1996.

[2] J. Gallagher, I. Macadam, J. Sayer, and L. P. van Lavieren, "Pulmonary tuberculosis in free-living lechwe antelope in Zambia," Tropical Animal Health and Production, vol. 4, no. 4, pp. 204-213, 1972.

[3] G. Kalema-Zikusoka, R. G. Bengis, A. L. Michel, and M. H. Woodford, "A preliminary investigation of tuberculosis and other diseases in African buffalo (Syncerus caffer) in queen Elizabeth national park, Uganda," Onderstepoort Journal of Veterinary Research, vol. 72, no. 2, pp. 145-151, 2005.

[4] M. Munyeme, J. B. Muma, V. M. Siamudaala, E. Skjerve, H. M. Munang'andu, and M. Tryland, "Tuberculosis in Kafue lechwe antelopes (Kobus leche Kafuensis) of the Kafue Basin in Zambia," Preventive Veterinary Medicine, vol. 95, no. 3-4, pp. 305-308, 2010.

[5] A. R. Renwick, P. C. L. White, and R. G. Bengis, "Bovine tuberculosis in southern African wildlife: a multi-species hostpathogen system," Epidemiology and Infection, vol. 135, no. 4, pp. 529-540, 2007.

[6] R. G. Bengis, R. A. Kock, and J. Fischer, "Infectious animal diseases: the wildlife/livestock interface," Revue Scientifique et Technique de l'OIE, vol. 21, no. 1, pp. 53-65, 2002.

[7] L. A. L. Corner, "The role of wild animal populations in the epidemiology of tuberculosis in domestic animals: how to assess the risk," Veterinary Microbiology, vol. 112, no. 2-4, pp. 303-312, 2006.

[8] M. Munyeme, L. Rigouts, I. C. Shamputa et al., "Isolation and characterization of mycobacterium bovis strains from indigenous zambian cattle using spacer oligonucleotide typing technique," BMC Microbiology, vol. 9, Article ID 144, 2009.

[9] H. M. Munag'andu, V. M. Siamudaala, A. Nambota et al., "Disease constraints for utilization of the African buffalo (Syncerus caffer) on game ranches in Zambia," The Japanese Journal of Veterinary Research, vol. 54, no. 1, pp. 3-13, 2006.

[10] A. E. Jolles, "Population biology of African buffalo (Syncerus caffer) at Hluhluwe-Mfolozi park, South Africa," African Journal of Ecology, vol. 45, no. 3, pp. 398-406, 2007.

[11] J. J. R. Grimsdell, "Age determination of the African buffalo, Syncerus caffer sparrman," East African Wildlife Journal, vol. 11, no. 31, p. 54, 1973.

[12] OIE, Manual of Diagnostic Tests and Vaccines for Terrestrial Animals, OIE Manual, 5th edition, 2004.
[13] U. Zieger, G. S. Pandey, N. P. J. Kriek, and A. E. Cauldwell, "Tuberculosis in Kafue lechwe (Kobus leche kafuensis) and in a bushbuck (Tragelaphus scriptus) on a game ranch in central province, Zambia," Journal Of The South African Veterinary Association, vol. 69, no. 3, pp. 98-101, 1998.

[14] M. Munyeme, J. B. Muma, E. Skjerve et al., "Risk factors associated with bovine tuberculosis in traditional cattle of the livestock/wildlife interface areas in the Kafue basin of Zambia," Preventive Veterinary Medicine, vol. 85, no. 3-4, pp. 317-328, 2008.

[15] G. S. Pandey, Studies of the Infectious Diseases of the Kafue Lechwe (Kobus leche kafuensis) with Particular Reference to Tuberculosis in Zambia, Azabu University, Tokyo, Japan , 1998.

[16] J. F. T. Griffin, J. P. Cross, D. N. Chinn, C. R. Rodgers, and G. S. Buchan, "Diagnosis of tuberculosis due to Mycobacteriumbovis in New-Zealand red deer Necrvus-Elaphus) using a composite blood-test and antibody-assays," The New Zealand Veterinary Journal, vol. 42, no. 5, pp. 173-179, 1994.

[17] V. M. Siamudaala, J. B. Muma, H. M. Munang'andu, and M. Mulumba, "Disease challenges concerning the utilization of the Kafue lechwe (Kobus leche kafuensis) in Zambia," in Conservation and Development Interventions at the Wildlife/Livestock Interface, Implications for Wildlife, Livestock and Human Health, O. Osofsky, S. Leaveland, W. B. Karesh et al., Eds., chapter 11, pp. 75-80, The International Union for Conservation of Nature, Gland, Switzerland and Cambridge, UK, 2005.

[18] D. Rottcher, "Wildlife diseases in Zambia-Final report," Department of Veterinary Services, Ministry of Agriculture Final report on wildlife diseases in Zambia, 93, German Agency for Technical Cooperation, Germany, 1978.

[19] A. E. Jolles, D. V. Cooper, and S. A. Levin, "Hidden effects of chronic tuberculosis in African buffalo," Ecology, vol. 86, no. 9, pp. 2358-2364, 2005.

[20] D. G. Grobler, A. L. Michel, L. M. de Klerk, and R. G. Bengis, "The gamma-interferon test: its usefulness in a bovine tuberculosis survey in African buffaloes (Syncerus caffer) in the Kruger National Park," Onderstepoort Journal of Veterinary Research, vol. 69, no. 3, pp. 221-227, 2002. 

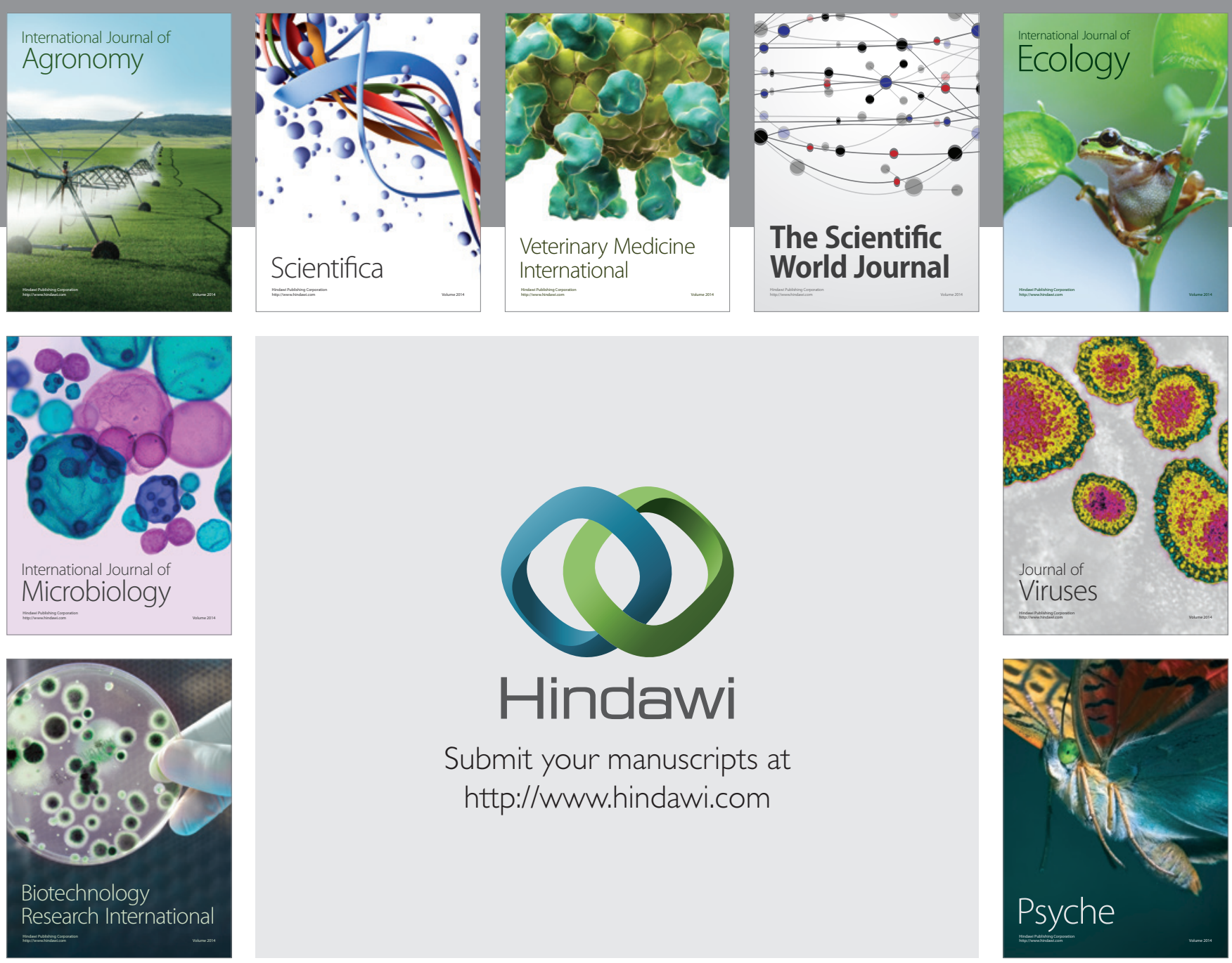

Submit your manuscripts at

http://www.hindawi.com
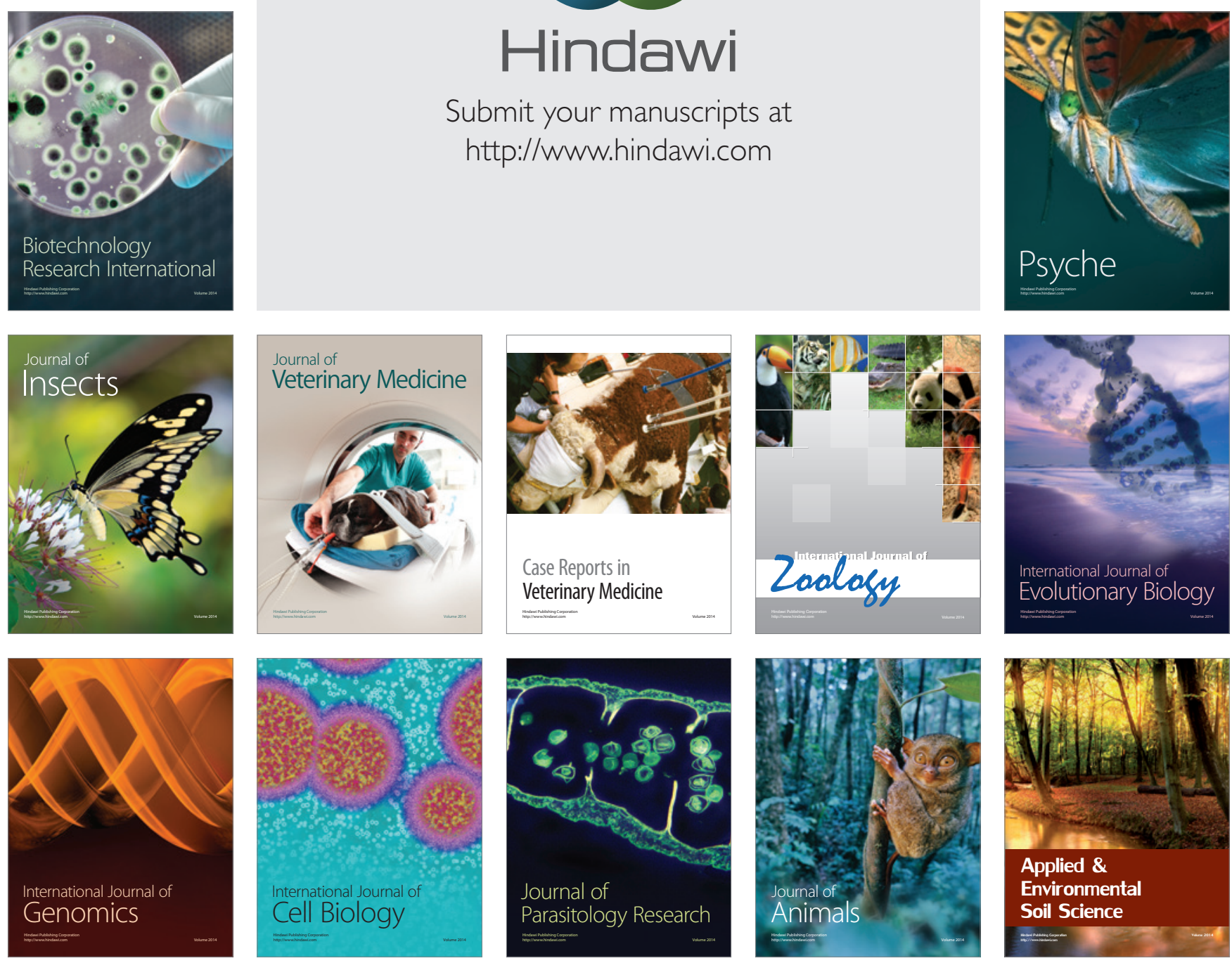